\title{
The Effect of Crack Geometry on the Nondestruc- tive Fault Detection in a Composite Beam
}

\author{
Sadettin Orhan \\ Ankara Yıldırım Beyazıt University, Mechanical Engineering Department, Ankara, Turkey \\ Murat Lüy \\ Kırıkkale University, Electrical \& Electronics Eng. Dept., 71450, Kırıkkale, Turkey
}

\author{
M. Hüsnü Dirikolu \\ Istanbul University, Mechanical Eng. Dept., 34320, Istanbul, Turkey
}

Gazi Mustafa Zorlu
TCDD, Ankara,Turkey

(Received 26 April 2014; accepted: 9 March 2015)

Defects in structures may be inherited from materials and manufacturing or they develop during service. Defects may cause catastrophic failure, which is why their detection and classification are important issues. Many aspects of defects have already been dealt with, but with wider applications of non-destructive testing methods to composite materials. However, the effect of arbitrary and random defect geometry on the applicability of these methods has been overlooked. In order to investigate this issue, this study carries out a free vibration analysis of a specially orthotropic cracked cantilever beam that was manufactured by Pultrusion. A new crack model, unlike the widely known V-shaped crack, is introduced and the effect of crack depth on the natural frequency is investigated, both experimentally and numerically. The results obtained from both the new- and the V-shaped models are compared with each other, and it is revealed that the results are not sensitive to the geometry change.

\section{INTRODUCTION}

Composites were used in various structural applications in the civil, automotive, and aerospace industries. One typical application of composites in structures are beams. A defect on a composite beam, which develops with time, can destroy it. Recent research has been directed to the detection or diagnoses of the development of defects in composites under dynamic loading. Initially, in composite failure detection research, Krawczuk et al. ${ }^{1}$ found that natural frequencies of a cracked structural composite member beam were influenced by a crack in the member: the increase in crack depth had caused a decrease in the calculated natural bending frequencies. Song et al., ${ }^{2}$ on the other hand, analysed that the bending free vibration of a cantilever laminated composite beam was weakened by multiple surface cracks. The governing equations of the composite beam with open cracks were accounted for in transverse shear and inertia effects. $\mathrm{Kisa}^{3}$ presented a new method for the numerical modelling of the free vibration of a cantilever composite beam that had multiple open and non-propagating cracks. The author had observed the frequency ratios to decrease under fibre angle increases. Wang et al. ${ }^{4}$ studied the coupled bending and torsional vibration of a fiber-reinforced composite cantilever with an edge surface crack. They concluded that changes in natural frequencies and the corresponding mode shapes depended on fiber orientation and fiber volume fraction. Finally, Hamid and Hamada ${ }^{5}$ investigated a composite beam with different fiber angles and a single crack. They stated that the natural frequency and the damping ratio increased when fiber angle rose for a constant crack location and depth.
Table 1. The mechanical properties of the pultruded GFRP composite beam.

\begin{tabular}{|c|c|c|c|c|c|c|c|c|c|}
\hline$E_{1}$ & $E_{2}$ & $E_{3}$ & $G_{12}$ & $G_{13}$ & $G_{23}$ & $v_{12}$ & $v_{13}$ & $v_{23}$ & Density \\
\hline \multicolumn{8}{|c}{$10^{9} \mathrm{~Pa}$} \\
\hline 25 & 8.5 & 8.5 & 3 & 3 & 3.9 & 0.23 & 0.23 & 0.09 & 1800 \\
\hline
\end{tabular}

In this study, a new crack model is introduced together with the known V-shaped crack model in order to investigate the effect of defect geometry change on the natural frequencies and mode shapes under free vibration loading. These examinations were carried out using both experimental and finite element analyses.

\section{MATERIAL PROPERTIES}

Material properties in the principal material directions 1, 2, and 3 of the pultruded glass fibre reinforced composite beam were determined. The beam had a solid cross-section with $45 \mathrm{~mm}$ height, $29 \mathrm{~mm}$ width, and a length of $1400 \mathrm{~mm}$. The 1axis lies along the fibre's direction and the shear modulus $G_{23}$ were calculated from Eq. (1):

$$
G_{23}=\frac{E_{2}}{2\left(1+\nu_{23}\right)} .
$$

The properties are given in Tab. 1 .

\section{NUMERICAL MODELLING}

ANSYS $8.1^{6}$ finite element package had been used to model the beam with an assumed open crack. The crack was created at $745 \mathrm{~mm}$ away from the cantilevered end. Eight different crack depths, namely $d=5,10,15,20,25,30$, and $35 \mathrm{~mm}$, 


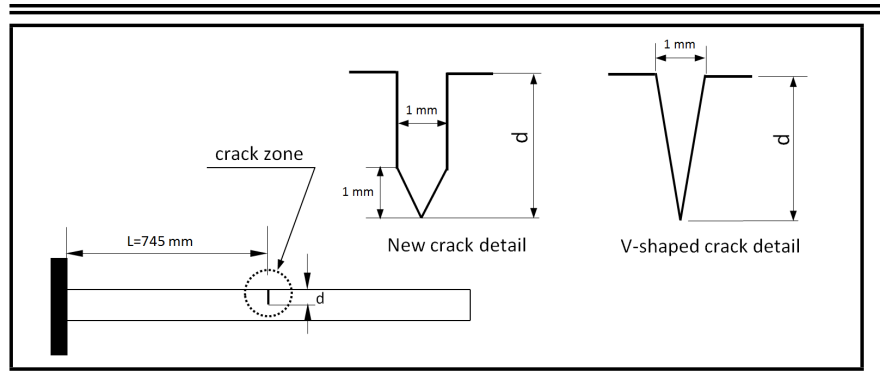

Figure 1. The schematic representation of the cracked cantilever beam.

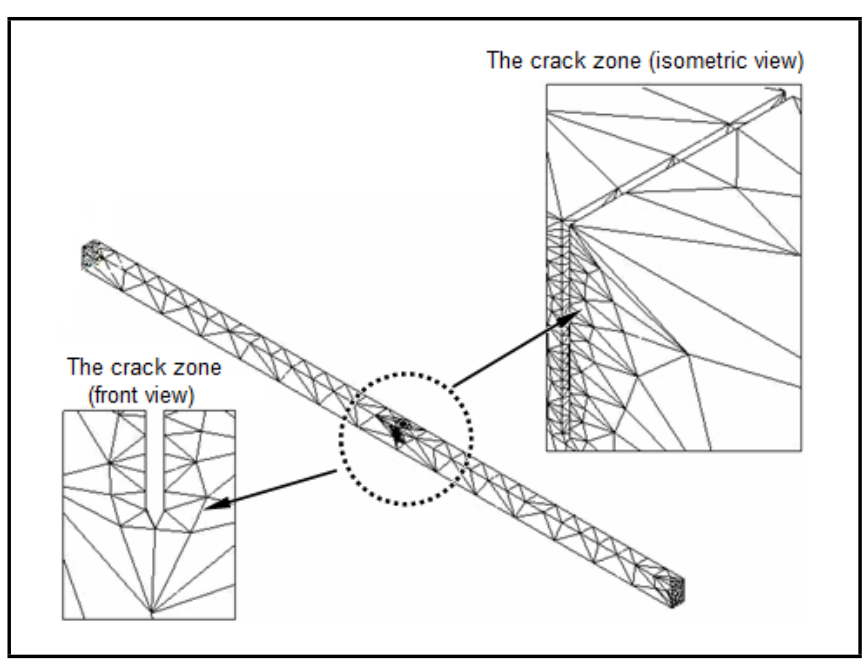

Figure 2. The overall appearance of the new finite element model and cracked zone.

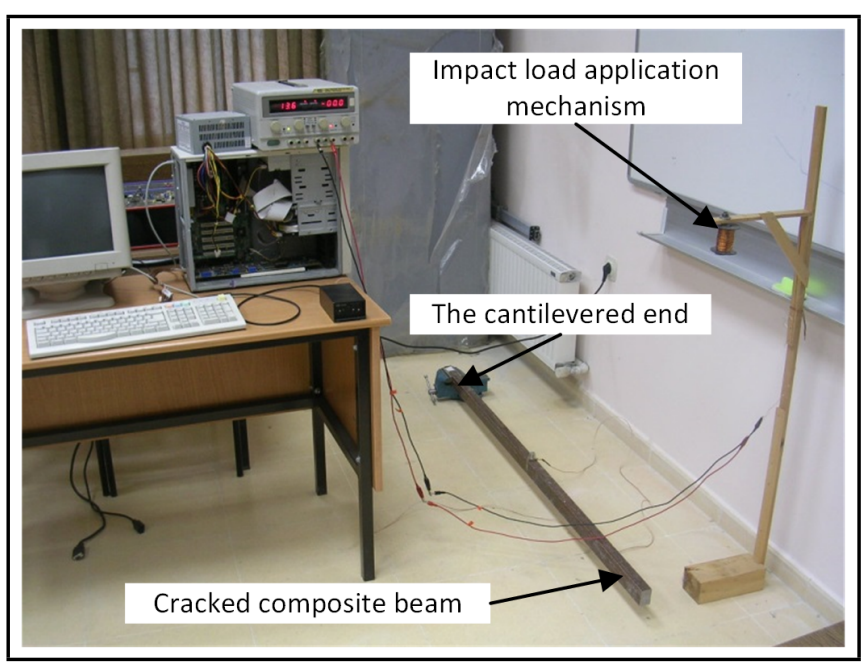

Figure 3. The experimental setup.

were studied. Lines were created by joining defined keypoints and the areas were obtained by connecting these lines. The three-dimensional beam models were obtained by extrusion of the corresponding areas along the width direction. Then, the model was meshed by Solid45 elements existing in the Ansys element library. Because the crack zone was the most critical, finer elements along the crack edges were created with constant $1 \mathrm{~mm}$ side length divisions. The overall appearance of the schematics and the finite element model are shown in Figs. 1 and 2, respectively.

Displacements and rotations of the left end of the beam in all directions were constrained. Hence, the cantilever boundary conditions were imposed. The upper side and the tip of the

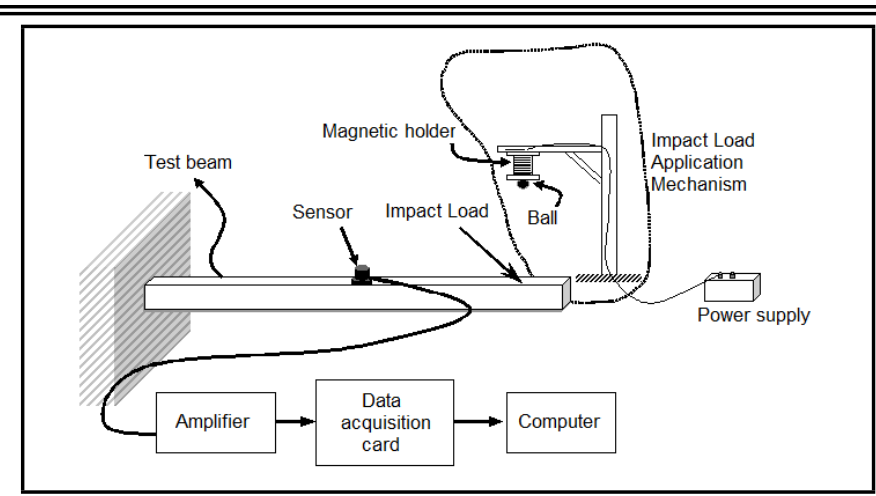

Figure 4. The schematic drawing of the experiment

crack were modelled in the shape of a combination of a rectangle and a V, as shown in Fig. 2. This was a different approach from previous research, where the whole crack had been modelled in a V-shape. In fact, cracks created on beams in real life have a rectangular upper side and a $\mathrm{V}$-shape towards the crack tip.

\section{EXPERIMENTS}

Both intact $(d=0)$ and cracked $(d=5,10,15,20,25,30$, and $35 \mathrm{~mm}$ ) specially orthotropic composite beams had been placed successively on the prepared setup for free vibration analysis. The experimental setup and its schematic drawing are shown in Figs. 3 and 4, respectively.

The intact beams were constrained from their left ends along a $100 \mathrm{~mm}$ length by the aid of a vice. An accelerometer was located at a point that is $700 \mathrm{~mm}$ away from the cantilever end. Free vibration was simulated by dropping a steel ball with a weight of 2.04 gram from a constant height of $800 \mathrm{~mm}$. Free vibration signals obtained through the accelerometer were amplified with an amplifier, which had a constant gain of 10 and transferred to the computer through a data acquisition card. The vibration signals were sampled with $100 \mathrm{kHz}$ on a data acquisition card. The data was then transferred to and recorded on the computer in $165 \mathrm{~ms}$. The computer recorded a total number of 16,384 data. Then, a program written in MATLAB was used to calculate Fast Fourier Transform of the vibration signals.

Later, artificial cracks that had widths of $1 \mathrm{~mm}$ and depths of $5,10,15,20,25,30$, and $35 \mathrm{~mm}$, respectively, and $745 \mathrm{~mm}$ away from the cantilever end were made by the aid of a hand saw. Experiments executed for the intact beam were also performed for every cracked beam, and the obtained data were saved to the computer.

\section{RESULTS AND DISCUSSION}

In this study, free vibrations of intact and later cracked beams that had different crack depths are investigated both experimentally and numerically. The natural frequencies of the beams are determined and then the relationship between the depth of the crack and the variation in the natural frequency is investigated. The first four experimental and finite element natural frequencies of the intact beam and the beams with the new crack model, along with the results of the V-shaped crack geometries, are presented in Tab. 2, where $f$ represents the corresponding natural frequency and $d$ shows the depth of crack with appropriate subscripts. Specifically, $d_{0}$ indicates the intact beam. Fig. 5 gives the lateral mode shapes for the $25 \mathrm{~mm}$ cracked depth, namely $d_{25}$. 
Table 2. The first four natural frequencies for the two crack geometries.

\begin{tabular}{||l|c|c|c|c|c|c|c|c||}
\hline Natural Freq. $[\mathrm{Hz}]$ & $d_{0}$ & $d_{5}$ & $d_{10}$ & $d_{15}$ & $d_{20}$ & $d_{25}$ & $d_{30}$ & $d_{35}$ \\
\hline$f_{1 \exp }$ & 18.80 & 18.75 & 18.75 & 18.75 & 18.75 & 18.75 & 18.75 & 18.75 \\
\hline$f_{1 \text { fem_New }}$ & 13.80 & 13.78 & 13.73 & 13.64 & 13.49 & 13.21 & 12.68 & 11.46 \\
\hline$f_{1 \_ \text {fem_V }}$ & 13.80 & 13.78 & 13.74 & 13.65 & 13.50 & 13.24 & 12.74 & 11.62 \\
\hline$f_{2 \exp }$ & 118.75 & 118.74 & 112.50 & 112.48 & 99.99 & 93.75 & 81.24 & 68.74 \\
\hline$f_{2 \text { fem_New }}$ & 85.35 & 84.87 & 83.28 & 80.65 & 76.58 & 70.65 & 62.62 & 52.09 \\
\hline$f_{2 \_ \text {fem_V }}$ & 85.35 & 84.91 & 83.44 & 80.86 & 76.93 & 71.20 & 63.41 & 53.04 \\
\hline$f_{3 e x p}$ & 331.23 & 331.23 & 324.96 & 324.95 & 318.73 & 312.48 & 306.22 & 299.98 \\
\hline$f_{3 \text { fem_New }}$ & 234.29 & 234.17 & 233.80 & 233.17 & 232.21 & 230.84 & 229.01 & 226.67 \\
\hline$f_{3 \_ \text {fem_V }}$ & 234.29 & 234.18 & 233.83 & 233.23 & 232.30 & 230.98 & 229.21 & 226.90 \\
\hline$f_{4 \text { exp }}$ & 624.96 & 612.46 & 606.20 & 599.96 & 587.46 & 568.71 & 556.21 & 543.71 \\
\hline$f_{4 \text { fem_New }}$ & 446.65 & 444.74 & 438.63 & 429.01 & 415.22 & 397.26 & 376.43 & 353.99 \\
\hline$f_{4 \_ \text {fem_V }}$ & 446.65 & 444.90 & 439.20 & 429.74 & 416.34 & 398.78 & 378.23 & 355.66 \\
\hline
\end{tabular}

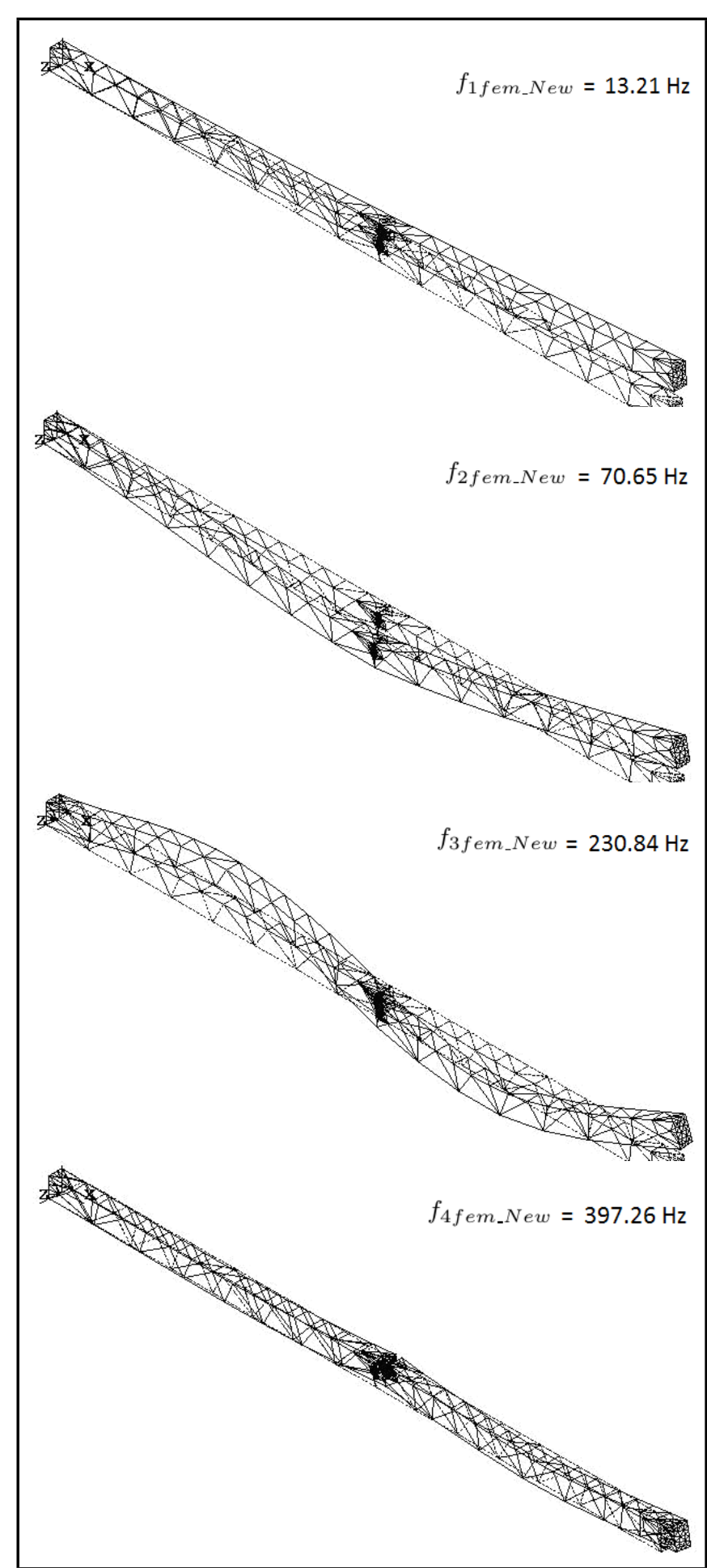

Figure 5. The mode shapes for the $25 \mathrm{~mm}$ cracked depth, namely $d_{25}$.
It is possible to diagnose the defects that arise in the course of time in structures by free vibration analysis. In this study, free vibrations of intact and cracked orthotropic composite beams that have different crack shapes are investigated both experimentally and numerically.

First of all, it has been found that the natural frequencies decrease when the depth of the crack increases in both experimental and finite element analyses for the new crack model. Additionally, as the depth of the crack increases, the error between finite element estimates and experiments varies from $22 \%$ to $39 \%$. This is believed to happen due to the structural instability created from higher crack lengths. Finally, the finite element natural frequency results obtained from both the new- and the V-shaped crack models are compared with each other and a maximum difference of $1.82 \%$ was determined. This result reveals that composite structures are insensitive to a change in crack shape geometry as long as vibration characteristics are concerned.

In conclusion, vibration monitoring on more complex structures can be coupled with finite element free vibration analysis in order to determine the severity of defects in such structures.

\section{REFERENCES}

1 Krawczuk, M., Ostachowicz, W. and Zak, A. Modal analysis of cracked, unidirectional composite beam, Composites Part B: Engineering, 28, 641-650, (1997). http://dx.doi.org/10.1016/S1359-8368(97)82238-X

2 Song, O., Ha, T. W. and Librescu, L. Dynamics of anisotropic composite cantilevers weakened by multiple transverse open cracks, Engineering Fracture Mechanics, 70, 105-123, (2003). http://dx.doi.org/10.1016/S00137944(02)00022-X

3 Kisa. M. Free vibration analysis of a cantilever composite beam with multiple cracks, Composite Science and Technology, 64, 1391-1402, (2004). http://dx.doi.org/10.1016/j.compscitech.2003.11.002

4 Wang, K. and Inman, D. J. Coupling of bending and torsion of a cracked composite beam, 22nd international modal analysis conference (IMAC), 26-29 January, Michigan, USA, 1460-1472, (2004). http://semproceedings.com/22i/sem.org-IMAC-XXII-Conf-s30p01Coupling-Bending-Torsion-Cracked-Composite-Beam.pdf

5 Abd El-Hamid Hamada, A. An investigation into the eigennature of cracked composite beams, Composite Structures, 38 (1-4),45-55, (1997). http://dx.doi.org/10.1016/S02638223(97)00040-8

6 ANSYS Release 8.1, ANSYS Inc., (2004). 